\title{
Preface: Special Issue on Selected Topics in Rock Mechanics and Rock Engineering
}

\author{
Pinnaduwa H. S. W. Kulatilake
}

Published online: 21 April 2012

(C) Springer Science+Business Media B.V. 2012

Seven papers are published in this special issue, each paper dealing with a different topic in rock mechanics and rock engineering, in the order given below. The first six papers are invited contributions. All 7 papers were peer reviewed using the standard procedure of the GEGE journal. The Guest editor was responsible for managing the peer review process for the first 6 papers. Professor Paul Marinos, one of the main editors of the journal, handled the peer review process for the last paper (by Kulatilake et al.). These papers provide either a state-of-the-art or a new development or both on the topic dealt with. All the papers have a very good balance between theory and practice. Therefore, the papers are useful for educators, researchers and practitioners.

Focusing on geologic carbon storage (gcs) in deep sedimentary formations, in particular saline aquifers, J. Rutqvist first provides a comprehensive review of the concept of storage, geomechanical processes and modeling tools associated with gcs, and issues related with such an operation. Then he provides detailed reviews on the following subtopics including a few case studies: (a) reservoir stress-strain and

P. H. S. W. Kulatilake ( $\square)$

Department of Materials Science and Engineering, University of Arizona, Tucson, AZ 85721, USA

e-mail: kulatila@u.arizona.edu

P. H. S. W. Kulatilake

Department of Mining and Geological Engineering,

University of Arizona, Tucson, AZ 85721, USA microseismicity, (b) gcs injectivity and limits on injection pressure, (c) wellbore integrity, (d) caprock sealing performance, and (e) potential for fault reactivation and earthquakes.

A. G. Thompson, E. Villaescusa and C. R. Windsor provide a comprehensive review on ground support terminology, classification and design based on a mechanistic approach. Detailed reviews are given on (a) ground support design, (b) reinforcement systems and (c) support systems. Design procedures cover both static and dynamic loadings. Authors hope that the material covered in the paper will assist in the design of efficient and effective ground support schemes appropriate to the prevailing rock mass conditions and the behavior of excavations.

W. Wittke, M. Wittke and J. R. Kiehl discuss the rehabilitation work performed for a historic gravity dam in Germany to ensure compliance with current, generally more stringent, design and operating standards. The performed field and laboratory investigations, monitoring and three-dimensional stability analyses using the finite element method are discussed in detail in the paper. The modeling has accounted for the interaction of dam and foundation rock and anisotropic mechanical and hydraulic behavior of the rock mass. A back analysis procedure has been used to calibrate the model parameters using the monitoring data.

H. Stille, G. Gustafson and L. Hassler describe a recently developed concept called the "Real Time Grouting Control Method (RTGC)" which is used to 
reduce the hydraulic conductivity and increase the stiffness of the rock mass to improve rock conditions under dams and foundations. RTGC deals with grout spread and measurement of grout flow and pressure in fractured rock with time in order to govern the grout spread in real time during the grouting operation. The concept was previously developed for pre-grouting of tunnels in fractured hard rock. The paper provides application of the method to two dam sites.

\section{A. Zang, O. Stephansson, O. Heidbach and} S. Janouschkowetz inform the current status on World Stress Map (WSM) and Quantitative World Stress Map (Q-WSM) in relation to rock mechanics and rock engineering using a large data base. Quality rankings are given for the maximum principal in situ stress direction obtained through borehole breakouts, drilling induced fractures, hydraulic fracturing, overcoring and borehole slotter techniques. Vertical and horizontal stress magnitudes and stress ratios are investigated in relation to depth, lithology and tectonic faulting regime.

A. Ghassemi provides a comprehensive review of the role of the following rock mechanics research topics on the development of geothermal systems: (a) in situ stress, (b) reservoir stimulation, (c) rock discontinuities, (d) coupled processes and permeability and (e) reservoir geodynamics and induced seismicity. The review on the aforementioned subtopics covers the currently used approaches, existing challenges facing the geothermal community, and how rock mechanics can contribute in their resolution.
P. H. S. W. Kulatilake, T. Hudaverdi and Q. Wu provide new models to predict mean particle size in rock blast fragmentation by applying multivariate statistical techniques (cluster, discriminant and regression analyses) and neural network methodology on a large data base that consists of blast design parameters, explosive parameters, modulus of elasticity and in situ block size. Prediction capability of the new models has been found to be better than the existing most applied fragmentation prediction model. Diversity of the blasts data used is one of the key aspects of the developed models.

My appreciation is extended to the authors of the papers for their hard and diligent work and producing excellent quality contributions. I would like to thank the reviewers of the papers for their in depth reviews and great efforts in improving the quality of the papers. Also, thanks are extended to Professor Marinos, Ms. Udayasree Daruvuru, who handled the Editorial Manager System for the special issue, and the publishing staff of the journal headed by Ms. Petra D van Steenbergen, Senior Publishing Editor of the journal, for their efforts and contributions in completing this special issue. All the aforementioned efforts were very important in making this special issue a success. 